\title{
Capital Flows to Developing Countries: Trends, Volatility and Policy Implications
}

\section{Oliver Morrissey and Robert Osei*}

\section{Introduction}

Capital inflows are a fundamental element in economic performance. Such inflows are essential to finance investment and economic policy is sensitive to the mobility of capital given the globalisation of capital markets. Economic policy and performance influences inflows and these inflows in turn have implications for macroeconomic management. The economic implications will depend on the type of inflow, whether official (aid) or private capital. Developing countries, including the poorest (predominantly, but not exclusively, in sub-Saharan Africa), are trying to attract increased levels of private inflows, especially foreign direct investment (FDI) but also other (short-term) private capital. This article reports results, with a central focus on sub-Saharan Africa (SSA), on capital inflows to identify trends and volatility (the extent of yearon-year changes) of different types of inflows and evaluate the influences for economic policy. Since the 1970s, what have been the trends in the level and composition of capital flows to developing countries, and what are the economic implications?

The analysis shows that although private capital flows to developing countries remain low (relative to gross domestic product, GDP), especially for the poorest countries, the 1990s have witnessed an increase. Although aid remains the most important capital inflow (relative to GDP) for developing countries, again especially the poorest, the composition is changing towards private inflows. While many would consider this increase in private inflows to be desirable, there are associated problems. Short-term (non-FDI) private capital is shown to be the most volatile type of inflow, i.e. there can be large year-on-year variations in the level of the flow (and large outflows are possible). If the composition of capital inflows is changing such that a greater share of inflows is inherently short term and mobile (i.e. volatile), there are implications for macroeconomic management. Governments want to reduce aid inflows and increase private inflows, so they aim for macroeconomic stability and growth. However, large inflows of private capital can undermine macroeconomic stability. Indeed, the volatility of private capital (the threat of an outflow) can precipitate an economic crisis even in countries with sound macroeconomic policies. This danger is explored in later parts of this article.

The article is organised as follows: Section 2 reports on the trends in different types of capital inflow, official and private, for developing countries (classified according to relative income) since the 1970s. The poorest countries are found to have become increasingly dependent on official (aid) inflows, although private inflows have begun to increase recently. Section 3 then considers the differences in the volatility of such inflows. Private inflows are found to be more volatile than official inflows. Although only relatively richer developing countries attract sufficient private inflows for this to be a matter of real concern, private inflows are increasing to poor countries. Section 4 presents a brief discussion of the determinants of capital inflows, to indicate the economic policies that attract private inflows. The conclusion in Section 5 considers the policy implications. The objective is to contribute to our understanding of how poor countries can influence and manage the composition of capital inflows.

\section{Trends in composition of capital inflows}

Private capital flows to developing countries increased substantially during the 1990s. Net private capital flows to low- and middle-income 
countries increased, in nominal terms, from US $\$ 42.6$ billion (of which US $\$ 24.1$ billion was FDI) in 1990 to US $\$ 267.7$ billion (US\$170.9 billion in FDI) in 1998 (World Bank 2000: 336). Net aid flows to developing countries declined during the period, from some US $\$ 60$ billion in 1993 to US $\$ 55$ billion in 1998 (World Bank 2000: 344). However, Gabriele et al. (2000) show that private capital inflows are increasingly concentrated in a small group of emerging markets, while most developing countries continue to face a severe scarcity of external resources. The composition has shifted in favour of private flows: these were about twothirds of the total in the 1970s, fell to 54 per cent in the 1980s, but rose thereafter and reached 80 per cent in the 1990s. Aid to developing countries reached a peak in relative terms in 1986 (at 25 per cent of inflows) then declined, falling below 10 per cent of total inflows from 1993. Other official flows have been unstable, surging in particular in 1995 and 1998 due to official intervention in the Mexican and Asian crises. The composition of private flows also changed - bank loans declined while both FDI (which is highly concentrated in a small number of countries) and portfolio inflows increased.

The volume of capital flows to SSA also increased in the 1990s, although estimates vary according to the source of data (Bhinda et al. 1999). There is a tendency for international organisations to underestimate the scale of capital flows given difficulties in collecting and assembling comparable data from national sources. Although only a small fraction of global FDI, FDI to SSA tripled between 1992 and 1995, growing fastest in some of the least developed economies, including Tanzania, Uganda and Ghana. The International Monetary Fund (IMF) and World Bank report that portfolio equity inflows are also rising fastest in SSA among developing country regions, albeit from a very low base. The level of net inflows through bank loans has decreased in SSA, although net short-term flows have risen in some countries, such as Tanzania since 1996 (Bhinda et al, 1999). Thus, private inflows are increasing and, although they remain low for most poor countries, they are rising quickly for some countries.

There are many different types of capital flow, and their importance to specific countries differs. The analysis concentrates on four types of capital flows - two private (FDI and other private capital,
OPC), and two official: official development assistance and official development finance (ODA and ODF). Remittances are important inflows to developing countries, but could not be separately identified; in the statistics used, they could be classed as FDI or OPC. The definitions used were:

- Foreign direct investment (FDI): net inflows of investment with the aim of acquiring a lasting management interest in a firm or enterprise. These are generally considered as relatively longterm flows.

- Other private capital (OPC): commercial bank lending, bonds, other private credit, non-debt flows and portfolio equity investments (excludes FDI). These are mostly short-term flows.

- Official development assistance (ODA): net disbursements of aid, grants and loans by the official sector at concessional financial terms.

- Official development finance (ODF): net disbursements of ODA plus non-concessional resources from multilateral and bilateral sources (including refinancing loans).

The level and composition of these flows can be expected to differ according to the level of development of different countries. Therefore, the developing countries in our sample are classified into four groups:

1. Low-income countries (LICs): economies in which per capita gross national product (GNP) in 1998 was at most US\$760. There are 29 countries in this group in our sample.

2. Lower-middle income countries (LMICs), in which per capita GNP in 1998 was within the range US $\$ 760$ to US $\$ 3,030$ (19 countries in this sample).

3. Upper-middle income countries, (UMICs), in which per capita GNP in 1998 was within the range US\$3,031 to US\$9,360 (12 countries in this sample).

4. Sub-Saharan African countries - separate results are presented for the 26 sub-Saharan African countries in the sample (only two of which were not LICs).

In general, the period under study is from 1970 to 1997 (for full details, see Osei et al. 2002). Table 1 summarises trends in the level of inflows (relative to GDP) for each group of countries. 
Table 1: Trends in capital inflows (ratios of GDP)

\begin{tabular}{|c|c|c|c|c|c|}
\hline & & FDI & OPC & ODA & ODF \\
\hline \multirow[t]{7}{*}{ Low-income countries } & 1970-1975 & 0.97 & 1.06 & 6.35 & 6.58 \\
\hline & $1976-1980$ & 1.04 & 2.09 & 8.28 & 9.18 \\
\hline & $1981-1985$ & 0.47 & 0.98 & 8.89 & 9.97 \\
\hline & $1986-1990$ & 0.51 & 0.07 & 12.00 & 12.89 \\
\hline & 1991-1995 & 0.82 & 0.03 & 14.50 & 14.83 \\
\hline & 1996-1997 & 1.44 & 0.17 & 12.21 & 12.61 \\
\hline & Entire period & 0.82 & 0.81 & 10.03 & 10.68 \\
\hline \multirow[t]{7}{*}{ Lower-middle income countries } & 1970-1975 & 1.20 & 1.35 & 3.23 & 3.56 \\
\hline & 1976-1980 & 1.13 & 2.35 & 4.49 & 5.23 \\
\hline & $1981-1985$ & 0.84 & 1.44 & 4.03 & 5.12 \\
\hline & $1986-1990$ & 1.32 & 0.54 & 4.18 & 5.04 \\
\hline & $1991-1995$ & 1.93 & 0.15 & 3.40 & 4.21 \\
\hline & 1996-1997 & 2.62 & 1.29 & 2.09 & 2.80 \\
\hline & Entire period & 1.38 & 1.18 & 3.72 & 4.46 \\
\hline \multirow[t]{7}{*}{ Upper-middle income countries } & 1970-1975 & 1.70 & 2.23 & 2.42 & 3.25 \\
\hline & $1976-1980$ & 1.56 & 3.15 & 1.62 & 2.00 \\
\hline & $1981-1985$ & 1.29 & 1.87 & 1.49 & 2.89 \\
\hline & $1986-1990$ & 1.34 & 0.45 & 1.22 & 2.27 \\
\hline & $1991-1995$ & 1.88 & 1.17 & 0.77 & 1.10 \\
\hline & 1996-1997 & 3.79 & 3.42 & 0.52 & 0.86 \\
\hline & Entire Period & 1.72 & 1.91 & 1.47 & 2.13 \\
\hline \multirow[t]{7}{*}{ Sub-Saharan Africa } & 1970-1975 & 0.85 & 0.90 & 6.97 & 6.38 \\
\hline & $1976-1980$ & 1.24 & 2.38 & 9.23 & 8.25 \\
\hline & 1981-1985 & 0.67 & 0.95 & 10.82 & 9.53 \\
\hline & 1986-1990 & 0.52 & 0.01 & 13.31 & 12.31 \\
\hline & 1991-1995 & 0.52 & -0.02 & 14.53 & 14.31 \\
\hline & 1996-1997 & 1.03 & 0.35 & 11.88 & 11.96 \\
\hline & Entire period & 0.78 & 0.81 & 10.15 & 10.89 \\
\hline
\end{tabular}

Notes: Figures are the mean for all countries in each sample of the average annual value of each capital flow for each period. The samples comprise 29 LICs, 19 LMICs, 12 UMICs and 26 SSA countries (not all of which are low-income).

Sources: Osei et al. (2002) and Morrissey (2003) for SSA.

Overall, the data shows that private inflows peaked in the late 1970s, albeit at very low levels for poor countries, but have declined steadily since then. Even upper-middle income developing countries recorded a poor performance on FDI and OPC prior to the late 1990s, when both categories exceeded 3 per cent of GDP, but for those countries FDI has been the larger inflow since the mid-1980s. The late 1990s witnessed a significant recovery in FDI, possibly reflecting increased privatisation, and a less pronounced increase in OPC (although there was a net outflow in the early 1990s). Table 1 shows that, in 1996-97, FDI inflows were larger than during any of the previous 5-year periods (except for sub-Saharan Africa).

These trends have continued into the 2000s: FDI inflows to developing countries increased steadily from US $\$ 152.7$ billion in 1996 to US $\$ 204.8$ billion in 2001, and FDI to SSA (excluding South Africa) increased from US $\$ 3.5$ billion to US $\$ 5.2$ 
billion over the same period (UNCTAD 2002: 303-304). By 2000, net private flows and FDI each amounted to about 2 per cent of GDP for SSA overall, although each was less than 1 per cent of GDP for low-income countries as a group (World Bank 2003: 238-241). Aid nevertheless remains the most important inflow for most developing countries, especially for the poorest.

In summary, Table 1 provides evidence that:

- Aid (ODA and ODF) represents the major source of capital inflow for the poorest developing countries (LICs and SSA). In rough terms, aid was 3-6 times private inflows in the 1970s, and about 13 times in the 1990s.

- Aid flows have become increasingly important for poor countries, increasing from some 6-9 per cent of GDP in the 1970s to $12-15$ per cent in the 1990s. Almost all of these aid flows are in the form of overseas development assistance (ODA). The non-concessional component of official development finance (the difference between ODA and ODF) accounts for less than 1 per cent of GDP for the low-income countries for all of the time periods.

- Private capital inflows (FDI and OPC together) are very low for poor countries and have declined, from just over 3 per cent of GDP in the late 1970s to less than 2 per cent in the late 1990s (1996-97 in Table 1).

- For the poorest countries, FDI has been the most important private inflow since the 1980s. Since the mid-1980s, other private capital (OPC) flows have been less than 0.2 per cent of GDP.

- For LMICs, although aid was a more important source of capital in the 1970s, private capital inflows had become the more important inflow by the late 1990s.

- Since the mid-1980s, FDI has been the most important private capital inflow for LMICs (at least twice OPC).

- Private capital has always exceeded aid for UMICs. Aid (ODF) as a percentage of GDP has declined consistently to less than 1 per cent by the late 1990s. FDI increased relative to OPC for UMICs.

- Overall, total private capital inflows declined between the peak of the late 1970s and trough of the early 1990s, with OPC becoming less important relative to FDI, for all groups of countries.
Only the richer developing countries (UMICS) attract significant volumes of FDI and other private capital. Even for these countries, it was only the late 1990s that both inflows exceeded 3 per cent of GDP.

The trends confirm what would have been expected a priori. Official flows, in particular aid, are the most important for poor countries and have become of increasing importance over time. Private capital inflows declined (relative to GDP) during the 1980s in particular. The decline in FDI inflows had reversed by the late 1990s, but flows of other private capital have only begun to recover in recent years. The poorest countries have become increasingly reliant on aid, attracting almost no private capital and little FDI. Other (non-FDI) private capital is only significant relative to GDP for the UMICs.

\section{Volatility of capital inflows}

Some characteristics of the changing composition of increased capital flows, as short-term private capital becomes more important, can generate serious problems (Gabriele et al. 2000). For example, short-term inflows such as investing in equity or bond markets are volatile and are thus a less reliable source of capital inflow. Financial liberalisation, by attracting short-term inflows, exposes host countries to instability. Foreign investors will have limited information about the nature of the market in developing countries, especially small ones, and will not be able to monitor how the funds are used locally. Foreign investors tend to act together (herding) and respond quickly to new information (which may reflect market sentiment rather than actual macroeconomic indicators), so rapid outflows may occur if confidence in a country declines. Developing countries are exposed to volatile private capital flows and contagion effects (a lack of confidence in one market quickly spreads to other countries). The result is that an economic crisis can occur in a country even where macroeconomic fundamentals are sound.

Other types of capital inflow tend to be more stable and predictable, and therefore pose fewer challenges for macroeconomic management. FDI is a relatively long-term commitment; while the level of inflows may vary from year to year, outflows of FDI are quite rare. Thus, FDI would be expected to be less volatile than other private inflows. 
Similarly, although the level of aid inflows can vary from year to year, aid would be expected to be less volatile than other inflows. These expectations are evaluated in our analysis, by considering volatility of different types of inflows to developing countries.

We are here concerned with how volatile capital flows have been. That is, we want measures that capture the year-on-year variability of the flow, and that summarise this volatility over the whole period. In economic terms, the major importance of capital inflows is to finance investment (in the case of aid, financing government spending in general is important). Investment decisions require planning and access to funds, so the predictability of inflows is important. High volatility should be associated with low predictability, and may therefore discourage investment. On the other hand, economic and political instability in a country may discourage inflows, and thus be associated with volatility. Consequently, volatility is a useful indicator in two respects - it captures disincentives to investment and reflects instability in the economy. Both are negatively associated with economic performance - see Lensink and Morrissey (2000) in the context of aid volatility, and Lensink and Morrissey (2001, 2002) in the context of FDI volatility.

For each type of inflow, we computed and compared three different measures of volatility (formal definitions can be found in Osei et al. 2002):

- The coefficient of variation $(\mathrm{CoV})$ : expresses the standard deviation as a percentage of the mean value for the series over time. This can be interpreted as a simple statistical measure of overall volatility during the period.

- The SDT Index: the standard deviation around a simple time trend (SDT) (variations of this measure are most commonly used in the literature). This can be interpreted as de-trended volatility over the period expressed as a percentage of the mean. A comparison between the $\mathrm{CoV}$ and SDT measures indicates how much of the volatility can be attributed to the trend over time. Typically, the SDT index will be lower; if it is considerably lower, this indicates that the trend is important, whereas if the two measures are quite close, there is no evident trend.

- The SDF Index: the standard deviation around a forecast value (SDF), intended to represent unanticipated volatility (this measure is developed and explained in Osei et al. 2002).
Essentially, past values are used to forecast future values so, in principle, the forecast trend can be anticipated (from past values). The SDF Index is based on the assumption that a forecast based on recent values is a better representation of the pattern than a simple time trend. If this assumption is true, SDF volatility will be lower than SDT, implying that one could predict or anticipate some volatility by using the forecast (compared with a time trend).

Table 2 presents all three measures for each flow to each group of countries to indicate the range of estimates of volatility over the period 1970-97. For the LICs aid (ODA) is slightly more volatile than ODF and for both CoV is much higher than either index, implying that much of the overall variation is due to trends. Volatility of aid flows to LICs is 14-18 per cent (of the mean). These official flows are considerably less volatile than private flows. Volatility of FDI to LICs was 45 per cent, but 70 per cent for OPC (SDF measure). The overall volatility values for flows to SSA are given in the last panel. It is evident that official flows (ODF) are by far the least volatile, and these have followed a significant trend (SDT is lower than $\mathrm{CoV}$ ). Volatility of private capital flows has been much higher, especially for OPC. While OPC was more volatile than FDI, there is more evidence of a predictable pattern (whereas there is no evidence for a trend in FDI); the "forecast" (SDF) approach reduces the estimate of volatility by almost a third compared to $\mathrm{CoV}$. We can note that private flows to SSA exhibit greater volatility than observed for low-income countries as a group, and that this level of volatility is higher than for lower-middle and upper-middle income countries, irrespective of the volatility measure employed.

For LMICs the overall volatility of aid flows is 24 per cent using the SDT measure and 15 per cent for the SDF measure (suggesting that about onethird of the volatility from a simple trend could be "anticipated" using a forecast). The values for ODF are similar. Thus, the volatility of official flows is similar to that for the low-income countries, but this volatility appears to be more predictable. Instability of private flows to LMICs was higher than for official inflows, 30-42 per cent for FDI and 60-80 per cent for OPC.

As might be expected, instability for UMICs is lowest for ODA at 13-15 per cent, but highest for 
Table 2: Instability of capital flows (entire period, flows to all countries)

\begin{tabular}{|c|c|c|c|c|c|}
\hline & & FDI & OPC & ODA & ODF \\
\hline \multirow[t]{3}{*}{ Low-income countries } & CoV & 47.68 & 113.14 & 31.89 & 29.98 \\
\hline & SDT & 48.52 & 93.51 & 14.47 & 13.39 \\
\hline & SDF & 44.59 & 69.54 & 17.85 & 16.82 \\
\hline \multirow[t]{3}{*}{ Lower-middle income countries } & CoV & 41.64 & 79.73 & 24.01 & 22.37 \\
\hline & SDT & 33.14 & 72.07 & 24.15 & 22.79 \\
\hline & SDF & 29.74 & 60.25 & 14.68 & 13.63 \\
\hline \multirow[t]{3}{*}{ Upper-middle income countries } & CoV & 46.24 & 62.99 & 44.02 & 46.56 \\
\hline & SDT & 44.36 & 60.82 & 14.50 & 35.87 \\
\hline & SDF & 38.80 & 46.36 & 13.36 & 22.60 \\
\hline \multirow[t]{3}{*}{ Sub-Saharan Africa } & CoV & 63.56 & 131.35 & 31.03 & 27.72 \\
\hline & SDT & 62.53 & 117.07 & 14.30 & 13.75 \\
\hline & SDF & 74.31 & 88.78 & 18.04 & 16.37 \\
\hline
\end{tabular}

Notes: Estimates based on total flows for each category to all countries in each group. Instability measures as defined in text.

Sources: Osei et al. (2002) and Morrissey (2003) for SSA.

ODF at 23-36 per cent. It is non-aid official flows that are most volatile (and note that non-aid official flows are more important for UMICs). The SDF measure is considerably lower than SDT, implying that more than a third of instability can be captured by the forecast as compared to the trend estimate. Instability of private flows to UMICs was greater than to LMICs for FDI at 39-46 per cent but lower for OPC at 46-63 per cent. In all cases, SDF gave lower instability than SDT, often considerably so (implying that the forecast is a better representation than a simple time trend). In general, the SDF measure gives lower volatility, implying that analysts for individual countries should attempt forecast equations to get the "best" estimate of future flows for policy and planning purposes.

In summary, Table 2 provides evidence that:

- official flows are less volatile than private flows;

- for most countries, ODA is slightly more volatile than ODF (and most ODF in such countries comprises ODA). Only in the UMIC group is ODF more volatile than ODA, and in these countries the ODA share is relatively low;

- volatility in FDI is lower than in other private flows, often considerably so;
- all capital inflows are, however, quite volatile and in general most of this volatility is not predictable;

- private capital flows to the LICs and SSA are more volatile than flows to the lower-middle and of the middle-income countries.

Osei et al. (2002) also present data on the trend in volatility, based on the annual average change in SDF in each period. In general, volatility was greatest in the 1970s but has been declining (the yearly average over the whole period is negative in most cases). This is somewhat misleading as, for most flows, volatility declined significantly in the 1970s but has increased since then. FDI is the only flow that has shown a steady decline in volatility in all periods, while volatility of OPC has been increasing since (albeit not relative to) the very volatile 1970 s.

\section{Determinants of capital inflows}

Governments of developing countries generally aim to attract private capital, partly because they want to reduce dependence on aid and partly because of the belief that private inflows are "good for growth" (institutions such as the World Bank 
and IMF typically promote private capital in this way). While there is evidence that FDI contributes to growth (Lensink and Morrissey 2001), the effect is weak for developing countries (Lensink and Morrissey 2002). We are not aware of any evidence showing that other private capital contributes to growth in developing countries (possibly because, historically, the inflows have been small). In policy terms it is quite important to distinguish FDI and non-FDI private inflows. This is not only because different factors may be more important in attracting each type of inflow, but also because governments may prefer to attract one rather than the other. In particular, FDI is generally a more stable source of investment finance and presents fewer problems of macroeconomic management than non-FDI private inflows (as these short-term inflows tend to be very volatile).

Private capital flows have usually been explained by two sets of factors - the "push" and "pull" factors. The push (external) factors relate to how economic conditions in the source countries affect the volume of global private capital flows. These external factors explain total global private capital outflows rather than how these flows are distributed across recipient countries. The pull (or domestic) factors aim to capture the determinants of cross-country variation in private capital inflows. The basic finding is that favourable macroeconomic performance increases private returns on investments and attracts private capital to the country. Two main channels are identified. The first relates to the productivity gains that result from increased confidence in the macroeconomic environment. Private investors move into these countries (or geographic regions) to take advantage of these productivity gains. A second channel is factors that make the receiving country more creditworthy (e.g. a stable exchange rate or falling debt burden). While studies have not identified a definitive set of determinants of private inflows, we identify some factors that are likely to be important for private flows to poor developing countries.

The following factors are quite consistently found to influence FDI:

- Growth is certainly important in attracting FDI, as such investment is seeking relatively longrun opportunities.

- Trade is a significant factor associated with FDI, and this applies to both importing and exporting.
Foreign investors appear to be attracted by more open trade regimes, either producing importcompeting goods to serve the domestic market or for export production. The former is more likely if the market is growing, and may also be attracted by regional integration.

- FDI does not seem to be associated with other capital inflows, whether private or official. In other words, other than growth (which is an influence on all capital inflows), the factors influencing FDI seem to be independent of the factors influencing other inflows. This may be because FDI responds to country-specific opportunities.

- Current FDI inflows are the best indicator of future FDI, and FDI is the most stable private capital inflow.

Few factors have been identified as robust determinants of non-FDI private inflows to lowincome countries such as those in SSA. The level of credit available to the private sector (an important economic indicator for investors) is one of the few factors consistently and positively associated with short-term capital inflows. Financial liberalisation may be the relevant policy option to attract nonFDI private capital. Non-FDI private capital tends to go only to richer countries, so sustained growth is especially important. This is a reason why flows to SSA and other poor countries are so low. There is a negative association between aid inflows and non-FDI private inflows. This is largely a reflection of the fact that poorer countries receive more aid.

Thus, countries trying to attract increased private capital should aim for economic growth and stable macroeconomic indicators (especially keeping control over domestic credit expansion). Trade policy and country-specific factors (such as availability of skilled labour or natural resources) are important for FDI, but it is macroeconomic factors that are most important for non-FDI private inflows. As discussed in the final section, private capital inflows can affect, as well as being attracted by, macroeconomic policy.

\section{Conclusion: is volatility a cause for concern?}

The recent increase in global capital flows to developing countries is a recovery (in terms of inflows/GDP ratios) in comparison to a decline in the 1980s. The volume of capital flows to low- 
income and SSA countries increased in the 1990s, but most of the increase was accounted for by aid (reflecting the generally poor economic performance of these countries). Only in the latter half of the 1990s (1996-97 in our data, but other sources show a continuing trend) is there some evidence of increasing private inflows, and most of this is FDI. What we observe is that private capital flows to low-income and SSA countries have been both small (relative to GDP) and highly volatile. Evidently, poor countries have not succeeded in attracting sustained inflows of private capital.

Private capital flows to SSA excluding FDI were negligible at only about 0.35 per cent of GDP in 1996-97. A realistic target would be at least three times this level: by the late 1990s, non-FDI private flows amounted to over 3 per cent of GDP in upper middle-income countries and over 1 per cent in lower middle-income countries. Private inflows reached 2 per cent of GDP in SSA around 2000, but it is not evident this has or can be sustained. The danger with non-FDI private capital is that volatility is very high. This poses challenges to macroeconomic management and it is these that we now consider.

\subsection{Macroeconomic policy challenges}

Shibata and Morrissey (2002) address the macroeconomic implications of increased private capital inflows to SSA in the context of theories of financial crisis. Private capital flows, especially OPC, are more volatile than official inflows and hence pose a challenge to macroeconomic stability. A sudden reversal of capital inflows was one factor underlying the East Asian crisis of 1997 as it contributed to a currency crisis. The literature on the East Asian crisis has identified a number of "crisis indicators", such as the rate of domestic credit expansion and level of foreign exchange reserves. In particular, the nature of the exchange rate regime is central to managing capital inflows and vulnerability to crisis. Shibata and Morrissey (2002) examine trends in exchange rate regimes and crisis indicators for five SSA countries in the 1990s (Ghana, Kenya, Malawi, Tanzania and Uganda). Although none of the indicators suggest that managing private flows posed a problem to the economies prior to the latter half of the 1990s, there were indications of potential problems if the volume of volatile private inflows were to increase.

The major problem that is identified is the prevalence of large trade deficits that could be exacerbated by exchange rate appreciation. Capital inflows are associated with pressures for appreciation, which is attractive to investors, whereas large current account deficits suggest the need for devaluation, which meets trade policy objectives (helps exporters). The conflicting exchange rate pressures associated with capital inflows and trade objectives need to be recognised by policy makers. Investors can be expected to monitor trade deficits, credit expansion, reserves and exchange rate pressures. Consequently, the domestic authorities responsible for managing capital inflows should be aware of these indicators of concern to investors. The analysis highlights two specific issues for macroeconomic policy-exchange rate management and exposure to risky international capital markets.

First, many SSA countries have moved from a fixed to floating exchange rate system since the 1980s, while actively trying to attract increasing private capital inflows. Although this has met with only limited success, many SSA countries (and other developing countries) are facing increased exposure to volatile private capital flows. This has created pressure for a real appreciation in many countries. Countries could consider introducing some capital controls while promoting domestic institutional development in the financial and banking sectors.

Second, an increasing dependence on "volatile" private foreign capital invites risk. A potential source of shock is the high level of trade deficits that may be unsustainable in many countries. Foreign investors tend to interpret a deficit as a sign of imminent devaluation, which threatens the value of their investments. Macroeconomic stability is threatened by volatile capital flows controlled by powerful private agents subject to unpredictable herd behaviour. As information quality is relatively low for poor countries in particular, and there are likely to be many small investors, susceptibility to herd behaviour is a potential problem. A particular aim should be improving the quality of information available to investors. One example is to provide regular "investor briefings" that review the performance of important indicators. The most relevant indicators are the expansion of domestic credit, the level of foreign reserves, the trade deficit and exchange rate. Such information should be made easily available and trustworthy. Institutions such as the IMF and the World Bank could act in 
a financially expansive, counter-cyclical fashion to offset herd behaviour, panic and contagion effects. They could also, at least indirectly in their dealings with the country, provide "authority" to the information on indicators of the economy. It is important, however, that it is the developing countries themselves that are the providers of information, perhaps through the Central Bank.

\subsection{Policy implications}

For the majority of developing countries, especially the poorer ones (most SSA countries), the best prospects for attracting private capital are in respect of FDI. While sustained growth will attract foreign investors, there are many other factors that influence FDI, especially insofar as it responds to specific opportunities. Traditionally FDI has often reflected natural resource endowments, especially in extractive industries, and this will continue to be important for certain countries. More generally and recently, privatisation attracts foreign investors (hence FDI). This can be complemented by policies to increase the skill level of the workforce, investment in general education and provision of vocational training. Trade liberalisation, increased openness, also appears to attract FDI. All of these policies can be mutually reinforcing, as openness, higher levels of human capital, and FDI, all tend to contribute to growth.

The prospects for increasing short-term (nonFDI) private capital inflows to SSA economies are bleak. Private capital inflows are discouraged by the instability and weak economic performance that are features of poor countries. This may not be a serious disadvantage, as short-term inflows are volatile and pose problems for aspects of macroeconomic management. Short-term inflows

\section{Notes}

* This article is based on a study of 'Capital Flows to Developing Countries', supported by a research grant from DFID (R7624) as part of the Globalisation and Poverty Research Programme (www.gapresearch.org). are easily reversed in response to changes in market sentiment that are difficult to predict or control. While some capital controls can limit exposure to sudden outflows, the controls may distort FDI and trade financing. Without controls, volatile capital flows can create pressure on exchange rates and capital account management. Economies with high levels of short-term capital inflows are more susceptible to financial crises. The major policy dilemma is reconciling the conflicting pressures on the exchange rate: private investors will tend to favour appreciation, whereas trade objectives are often better served by devaluation.

The conclusion is a brief one: the major issue facing poor developing countries, such as SSA, is not the problems associated with volatile private capital inflows, it is (all the factors associated with) the difficulty of attracting such inflows. To date, SSA countries have failed to attract private capital in significant amounts. Aid is the major inflow, and it is vital that aid is used effectively to promote growth and stability. If this is achieved, the prospects for attracting private inflows, especially FDI (which offers the most promise) will improve. As shortterm private inflows increase, developing countries will be exposed to volatility and contagion effects (a lack of confidence in one market quickly spreads to other countries). The result is that an economic crisis can occur in a country even where macroeconomic fundamentals are sound. The policy action to reduce contagion effects is to provide better quality information on the "state of the economy" to investors. The major policy challenge associated with an increase in short-term private capital inflows relates to exchange rate management and policy makers should be aware of this.

$\begin{array}{ll}\text { Abbreviations } \\ \text { CoV } & \text { coefficient of variation } \\ \text { FDI } & \text { foreign direct investment } \\ \text { GDP } & \text { gross domestic product } \\ \text { GNP } & \text { gross national product } \\ \text { LICs } & \text { low income countries } \\ \text { LMICs } & \text { lower-middle income countries } \\ \text { ODA } & \text { official development assistance } \\ \text { ODF } & \text { official development finance } \\ \text { OPC } & \text { other private capital } \\ \text { SDF } & \text { standard deviation around a forecast value } \\ \text { SDT } & \text { the standard deviation around a simple time trend } \\ \text { SSA } & \text { sub-Saharan Africa } \\ \text { UMICs } & \text { upper-middle income countries }\end{array}$




\section{References}

Bhinda, N., Griffith-Jones S., Leape J. and Martin, M. (eds), 1999, Private Capital Flows to Africa: Perception and Reality, The Hague: Forum on Debt and Development (FONDAD)

Gabriele, A., Baratav, K. and Parikh, A., 2000, 'Instability and volatility of capital flows to developing countries', The World Economy, Vol 23 No 8: 1030-1056

Lensink, R. and Morrissey, O., 2002, 'The volatility of FDI, not the level, affects growth in developing countries', CDS Research Report 13, University of Groningen

Lensink, R. and Morrissey, O., 2001, 'Foreign direct investment: flows, volatility and growth', CREDIT Research Paper 01/06, Nottingham: University of Nottingham School of Economics

Lensink, R. and Morrissey, O., 2000, 'Aid instability as a measure of uncertainty and the positive impact of aid on growth', Journal of Development Studies, Vol 36 No 3: 31-49

Morrissey, O., 2003, 'Private Capital Flows to SubSaharan Africa', in Development Report 2003:
Finance for Development: Enhancing the Role of Private Finance, Midrand: Development Bank of South Africa (DBSA)

Osei, R., Morrissey, O. and Lensink, R., 2002, 'The volatility of capital inflows: measures and trends for developing countries', CREDIT Research Paper 02/20, Nottingham: University of Nottingham School of Economics

Shibata, M. and Morrissey, O., 2002, 'Are private capital inflows a potential problem for SubSaharan African countries?', CREDIT Research Paper 02/21, Nottingham: University of Nottingham, School of Economics

UNCTAD, 2002, World Investment Report 2002, Geneva: UNCTAD

World Bank, 2003, World Development Report 2003, Washington, DC: The World Bank and Oxford University Press

World Bank, 2000, World Development Indicators 2000, Washington, DC: The World Bank 